Article

\title{
A Biosensor for Urea from Succinimide-Modified Acrylic Microspheres Based on Reflectance Transduction
}

\author{
Alizar Ulianas, Lee Yook Heng * and Musa Ahmad \\ School of Chemical Sciences and Food Technology, Faculty of Science and Technology, \\ University Kebangsaan Malaysia, Bangi, Selangor 43600, Malaysia; \\ E-Mails: alizar_chem@yahoo.co.id (A.U.); andong@usim.edu.my (M.A.) \\ * Author to whom correspondence should be addressed; E-Mail: leeyookheng@yahoo.co.uk; \\ Fax: +60-3-8921-5410, Tel: +60-3-8921-3356.
}

Received: 25 July 2011; in revised form: 2 August 2011 / Accepted: 4 August 2011 / Published: 26 August 2011

\begin{abstract}
New acrylic microspheres were synthesised by photopolymerisation where the succinimide functional group was incorporated during the microsphere preparation. An optical biosensor for urea based on reflectance transduction with a large linear response range to urea was successfully developed using this material. The biosensor utilized succinimide-modified acrylic microspheres immobilized with a Nile blue chromoionophore (ETH 5294) for optical detection and urease enzyme was immobilized on the surface of the microspheres via the succinimide groups. No leaching of the enzyme or chromoionophore was observed. Hydrolysis of the urea by urease changes the $\mathrm{pH}$ and leads to a color change of the immobilized chromoionophore. When the color change was monitored by reflectance spectrophotometry, the linear response range of the biosensor to urea was from 0.01 to $1,000 \mathrm{mM}\left(\mathrm{R}^{2}=0.97\right)$ with a limit of detection of $9.97 \mu \mathrm{M}$. The biosensor response showed good reproducibility (relative standard deviation $=1.43 \%$, $\mathrm{n}=5$ ) with no interference by major cations such as $\mathrm{Na}^{+}, \mathrm{K}^{+}, \mathrm{NH}_{4}{ }^{+}$and $\mathrm{Mg}^{2+}$. The use of reflectance as a transduction method led to a large linear response range that is better than that of many urea biosensors based on other optical transduction methods.
\end{abstract}

Keywords: urea; reflectance; optical biosensor; succinimide; acrylic microspheres; photopolymerisation 


\section{Introduction}

Urea biosensors have been reported for urea determinations in biomedical, clinical and food industry applications [1-3], e.g., for monitoring of urea levels in human urine and blood for diagnosis of kidney function and health [4-6], as well as for the determination of urea levels in milk [2]. These numerous applications have motivated the development of urea biosensors. Urea biosensors have been developed using different transducers, including ion-selective field effect transistor electrode [7], ammonium ion-selective electrode [8], $\mathrm{CO}_{2}$ gas electrode [9], $\mathrm{pH}$ electrode [10] and ammonia gas selective electrode [11].

Many urease enzyme immobilization techniques for biosensor construction have involved the incorporation of the enzyme into a polymer membrane or polymer backbone such as tetrafluoroethylene and poly(tetrafluoroethylene) [1], chitosan membranes [12], sol-gel-derived thick-films [3,6] and $\operatorname{poly}(N$-vinylcarbazole $) /$ stearic acid [5]. Immobilization of urease in a membrane can lead to a loss of enzyme activity (deactivation and denaturation), as well as a decrease of the lifetime, sensitivity and poor response time of the biosensor. Therefore, it is essential to choose an enzyme immobilization technique that will enhance the operational and storage stability of the enzyme but at the same time avoid any interference of the immobilization matrix on enzyme activity [12-14]. Previously reported urease enzyme immobilization techniques include entrapment and encapsulation, covalent binding, cross-linking and adsorption [15]. Other published reports on the use of nanospheres for biosensors were based on poly-(styrene-co-acrylic acid) functionalized with dithioglycol [16,17] and poly(divinylbenzene-co-acrylic acid) [18] modified with gold nanoparticles for the immobilization of horseradish peroxidase enzyme. The use of spherical beads for immobilization of urease in biosensor is uncommon and no report in the use of acrylic microspheres for urea biosensor has been published to date. Nile-Blue chromoionophore is commonly used as an indicator in sol-gel film for biosensing of pesticides [19], in sol-gel [6] and in plasticized PVC membrane for biosensing of urea [20,21] with absorption optical detection mode.

In this research, acrylic microspheres modified with succinimide groups at the sphere surface were used to fabricate an optical urea biosensor based on a reflectance method. The microspheres serve two purposes, i.e., first to covalently immobilize urease on the surface of the spheres and secondly to entrap the chromoionophore as an indicator in the spheres. $N$-Acryloxysuccinimide was used to modify acrylic microspheres to produce functional groups as a linker to immobilize enzyme urease via covalent bonds. The efficiency of this bonding has be proven as reported [22,23]. The acrylic microspheres have the advantages of small size and providing a large surface area to volume ratio for enzymatic reactions to occur on the surface, in addition to preventing any barriers to diffusion of reactants and products. Thus this should improve biosensor performance in terms of response time and linear response range. The use of $n$-butyl acrylate in microsphere synthesis is also compatible with the hydrophobicity of the lipophilic chromoionophore ETH5294 where the chromoionophore is used in the reflectance mode instead of the commonly used absorption mode. In addition, microspheres made from $n$-butyl acrylate also possess good adhesion properties that allow these spheres to be coated directly on a plastic substrate for optical biosensor fabrication. 


\section{Experimental}

\subsection{Chemicals}

2-2-Dimethoxy-2-phenylacetophenone (DMPP) and 1,6-hexanadiol diacrylate (HDDA) were supplied by Aldrich. Sodium dodecyl sulfate (SDS), $N$-acryloxysuccinimide (NAS), urea, urease enzyme (E.C 3.5.1.5; 26.1 units/mg from Jack beans) and phenolphthalein (PP) were supplied by Systerm, Acros, Harnstoff, Sigma-Aldrich and Merck, respectively. Bradford Reagent and bovine serum albumin (BSA) were obtained from Sigma. Chromoionophores (ETH5294), $\mathrm{MgCl}_{2}$ and $\mathrm{K}_{2} \mathrm{HPO}_{4}$ were supplied by Fluka, while $\mathrm{KH}_{2} \mathrm{PO}_{4}$ and $n$-butyl acrylate (n-BA) were from Merck. $\mathrm{NaCl}$, $\mathrm{KCl}$ and dimethylformamide (DMF) were obtained from Systerm, $\mathrm{NH}_{4} \mathrm{Cl}$ from Comak and 4-(N-N-dimethylamino)-benzaldehyde (DMAB) from Riedel de Haën. All aqueous solutions were prepared using deionized water.

\subsection{Synthesis of Acrylic Microspheres}

A mixture of $450 \mu \mathrm{L}$ HDDA, $0.1 \mathrm{~g}$ DMPP, $6 \mathrm{mg}$ NAS and $15 \mathrm{~mL} \mathrm{H}_{2} \mathrm{O}$ with various amounts of $\mathrm{n}$-BA and SDS was sonicated for $10 \mathrm{~min}$, after which it was subjected to photopolymerisation for $600 \mathrm{~s}$ with UV light $(350 \mathrm{~nm})$ under nitrogen gas flow. The resulting acrylic microspheres were then collected by centrifugation at 4,000 rpm for $30 \mathrm{~min}$. These spheres were washed three times in phosphate buffer at $0.05 \mathrm{M}(\mathrm{pH} 7.0)$, then air dried. The size of the acrylic microspheres was determined using scanning electron microscopy (SEM, LEO 1450VP). A Microtrac-X100 particle sizer was used to determine the size distribution of the acrylic microspheres $(0.1 \mathrm{mg} / \mathrm{mL})$. FTIR spectra of acrylic microsphere were obtained using a Spectrum FTIR GX infra-red spectrophotometer (Perkin Elmer).

\subsection{Immobilization and Activity of Urease Enzyme}

The acrylic microspheres were coated onto a transparent plastic sheet by dipping the plastic sheet in the acrylic microsphere suspension just after photocuring and air drying at room temperature. A solution of $2 \mathrm{mg}$ of urease per $\mathrm{mL}$ of buffer was prepared in $0.05 \mathrm{M} \mathrm{pH} 7.0$ phosphate buffer solution. The urease was then immobilized onto the acrylic microspheres by immersing the microsphere-coated support in the urease enzyme solution for $24 \mathrm{~h}$ at $4{ }^{\circ} \mathrm{C}$. The acrylic microspheres with immobilized urease were then washed and kept in phosphate buffer solution at $\mathrm{pH} 7.0$ until use. The plastic support with no immobilized acrylic microsphere coating was used for the control experiments.

The amount of urease immobilized on these samples was then estimated by checking the enzyme activity. For this measurement, $10 \mathrm{~mL}$ of test solution containing urea and phenolphthalein was prepared in deionized water and used for all measurements. Enzyme activity was determined by immersing a plastic support coated with a known amount of enzyme-modified microspheres in the urea solution. Urea hydrolysis by the immobilized urease on the microspheres produced a change in $\mathrm{pH}$, which caused the test solution to turn pink. The enzyme urease catalyzes the urea hydrolysis to change $\mathrm{pH}$ according to the following reaction:

$$
\mathrm{H}_{2} \mathrm{~N}-\mathrm{CO}-\mathrm{NH}_{2}+3 \mathrm{H}_{2} \mathrm{O} \stackrel{\text { Urease }}{\longrightarrow} 2 \mathrm{NH}_{4}^{+}+\mathrm{HCO}_{3}^{-}+\mathrm{OH}^{-}
$$


The absorbance of the test solution was monitored for $30 \mathrm{~min}$ at a wavelength of $553 \mathrm{~nm}$ using the spectrophotometer.

\subsection{Enzyme Leaching Test and Effects of pH on Enzyme Immobilization}

To determine the effects of $\mathrm{pH}$ on the immobilization of the enzyme, urease enzyme solutions were prepared using phosphate buffer at pHs of 6.5, 7.0, 7.5 and 8.0. For the leaching test, a fixed amount of acrylic microspheres modified with immobilized urease were immersed in $0.05 \mathrm{M}(\mathrm{pH} 7.0)$ phosphate buffer solution, and $0.5 \mathrm{~mL}$ phosphate buffer solution was taken in every 10 min before mixing with $2.5 \mathrm{~mL}$ of urea solution $(1.0 \mathrm{M})$ and phenolphthalein indicator. The mixture was monitored for $90 \mathrm{~min}$, where the absorbance of that solution was periodically measured at a wavelength of $553 \mathrm{~nm}$ using the spectrophotometer.

\subsection{Determination of Urease Immobilized}

The amount of urease immobilized onto the urea biosensor and the influence of various immobilization times $(0.5$ to $24 \mathrm{~h})$ were quantified by Bradford reagent method [24] with bovine serum albumin (BSA) as a standard to quantify urease enzyme immobilization. Urease enzyme concentration for immobilisation studies was fixed at $2.0 \mathrm{mg} \mathrm{mL}$. The amount of immobilized enzyme was calculated according to the following equation:

$$
\% \text { urease immobilized }=\{(\mathrm{A}-\mathrm{B}) / \mathrm{A}\} \times 100 \%
$$

where $A$ is the amount of urease used and B is the urease left after immobilisation.

\subsection{Construction and Evaluation of Urea Biosensor Performance}

A sample of $375.0 \mathrm{mg}$ of dried acrylic microspheres, $300.0 \mu \mathrm{L}$ chromoionophore solution $\left(0.1 \mathrm{mg} \mathrm{mL}^{-1}\right.$ ethanol), $450.0 \mu \mathrm{L}$ ethanol and $125.0 \mu \mathrm{L}$ DMF were ultrasonically mixed for 3 min until homogeneous. After that $15.0 \mu \mathrm{L}$ of the suspensions were drop-coated onto a fixed size plastic support $(5.25 \pm 0.01 \mathrm{~mm}$ diameter and $0.56 \pm 0.05 \mathrm{~mm}$ thickness) and then dried at room temperature for $1 \mathrm{~h}$. Urease was then immobilized onto these microspheres by dispensing $100 \mu \mathrm{L}$ urease solution onto the support, then leaving it for $24 \mathrm{~h}$ at $4{ }^{\circ} \mathrm{C}$. A urea biosensor in the form of a test-strip was thus fabricated and ready for testing.

To evaluate the response of the urea biosensor to urea, the biosensor was tested with several concentrations of urea solution in the 0.001 to $1,000 \mathrm{mM}$ range in $0.05 \mathrm{M}$ phosphate buffer ( $\mathrm{pH}$ 6.5). The intensity of the color change of the urea biosensor was measured using a reflectance spectrophotometer (Mikropack DH-2000-Bal). Biosensors with varying amounts of acrylic microspheres $(0.64,6.43$ and $643 \mathrm{mg}$ ) at different analysis times $(5.0 \mathrm{~min}, 10 \mathrm{~min}$ and $20 \mathrm{~min}$ ) were also evaluated. The linear response range of urea for the biosensor was determined from plots of urea concentration versus intensity change as measured by the reflectance spectrophotometer.

Since the enzymatic hydrolysis of the urea and the protonation of chromoionophore can be affected by $\mathrm{pH}$, the working $\mathrm{pH}$ range of the optode was also optimized [20]. The effects of $\mathrm{pH}$ on the response of the urea biosensor was studied in phosphate buffer at pHs from 5.0 to 8.0 and with urea concentration fixed at $0.05 \mathrm{M}$. 


\subsection{Investigation of the Ionic Interference on the Optical Urea Biosensor}

To determine the applicability of the optical urea biosensor to real samples, the interference of ions typically found in urine such as $\mathrm{NH}_{4}^{+}, \mathrm{Na}^{+}, \mathrm{K}^{+}$and $\mathrm{Mg}^{2+}$ was studied under optimum condition where the urea biosensor was exposed to the interference at various concentrations ( 0.001 to $100 \mathrm{mM})$.

\subsection{Validation and Recovery Studies of Urea Biosensor}

For validation and recovery performance of the urea biosensor, urine samples were used as described previously [6]. A non-enzymatic method using $p$-dimethylaminobenzaldehyde (DMAB) [25] was used as comparison. Briefly, for the chemical analysis of urea, DMAB solution was prepared in ethanol and $\mathrm{HCl}$ and the range of the standard urea concentration used was 1.0 to $70.0 \mathrm{mM}$ to construct the calibration curve. For urine samples, urea concentrations of 1.01 to $69.94 \mathrm{mM}$ were spiked into the samples. These spiked urine samples were analyzed for urea with both biosensor and DMAB methods. The percentage of recovery of urea from all urea-spiked urine samples was determined by the urea biosensor method, calculated with the following equation:

$$
\% \text { Recovery }=\mathrm{Cs} / \mathrm{C} \times 100 \%
$$

where $\mathrm{C}$ is the actual concentration of urea and $\mathrm{Cs}$ is the concentration of urea determined by the biosensor in urea-spiked sample.

\subsection{Reproducibility and Stability of the Urea Biosensor}

The $\mathrm{pH}$ of the urea solution was kept constant during evaluation of the reproducibility and stability of the biosensor. Reproducibility of several urea biosensors using reflectance spectrophotometer were tested at a constant concentration of $10.0 \mathrm{mM}$ urea at $\mathrm{pH} 6.5$ (0.05 $\mathrm{mM}$ phosphate buffer). The constant reflectance response of each biosensor would indicate good reproducibility. Stability was determined by fabricating several urea biosensors, which were kept at $4{ }^{\circ} \mathrm{C}$ before used. Each biosensor was tested for up to 45 days using $1.0 \mathrm{mM}$ and $10.0 \mathrm{mM}$ urea in $\mathrm{pH} 6.5$ (0.05 mM phosphate buffer).

\section{Results and Discussion}

\subsection{Characterization of Acrylic Microspheres and Urease Immobilization}

In the FTIR spectrum of the acrylic microspheres (Figure 1), peaks at $1,188.99 \mathrm{~cm}^{-1}$ to $1,066.13 \mathrm{~cm}^{-1}$ are associated with the stretching frequencies of the $(\mathrm{C}-\mathrm{O})$ groups of the n-BA molecules and the succinimide ester $(\mathrm{C}-\mathrm{O})$ of the NAS molecules. The $\mathrm{C}-\mathrm{N}$ stretch peaks present at $1,256.42 \mathrm{~cm}^{-1}$ to $1,165.58 \mathrm{~cm}^{-1}$ are from the NAS molecules.

Urease can be immobilized onto the surface of the acrylic microspheres by covalent binding because the NAS succinimide ester groups are highly reactive towards enzyme amino groups [22] and thus the amino groups of the urease. 
Figure 1. FTIR spectrum of acrylic microspheres.

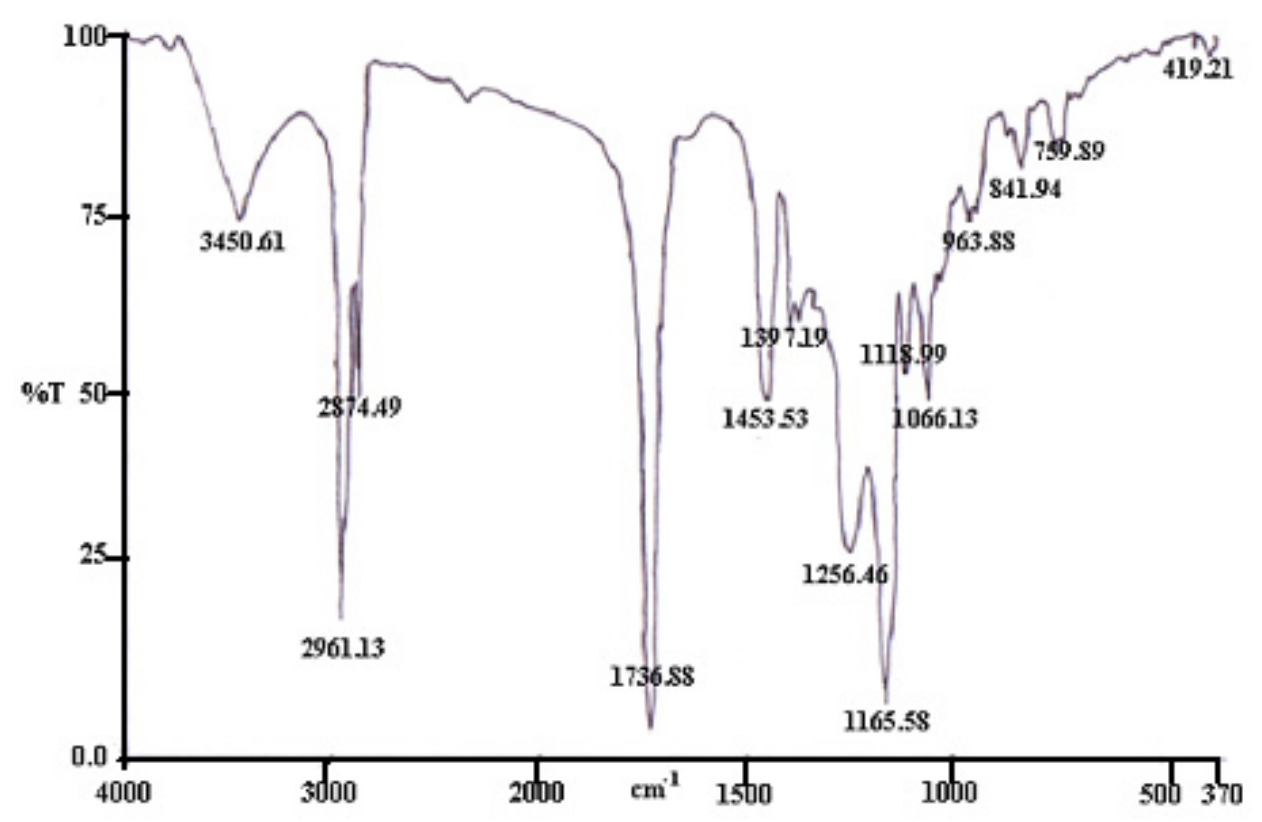

These spectra indicated that the acrylic microspheres had been modified with NAS. A typical scanning electron microscope (SEM) image of the acrylic microspheres (Figure 2) demonstrates that the size of the microspheres was approximately less than $5 \mu \mathrm{m}$ in diameter, depending on the amount of monomer and SDS used. However, when the size of the microspheres was determined by a particle sizer, a size of more than $5 \mu \mathrm{m}$ was predominant. This is because of aggregation of the acrylic spheres in solution phase during measurement when using a particle sizer.

Figure 2. SEM image of acrylic microspheres prepared from photopolymerisation.

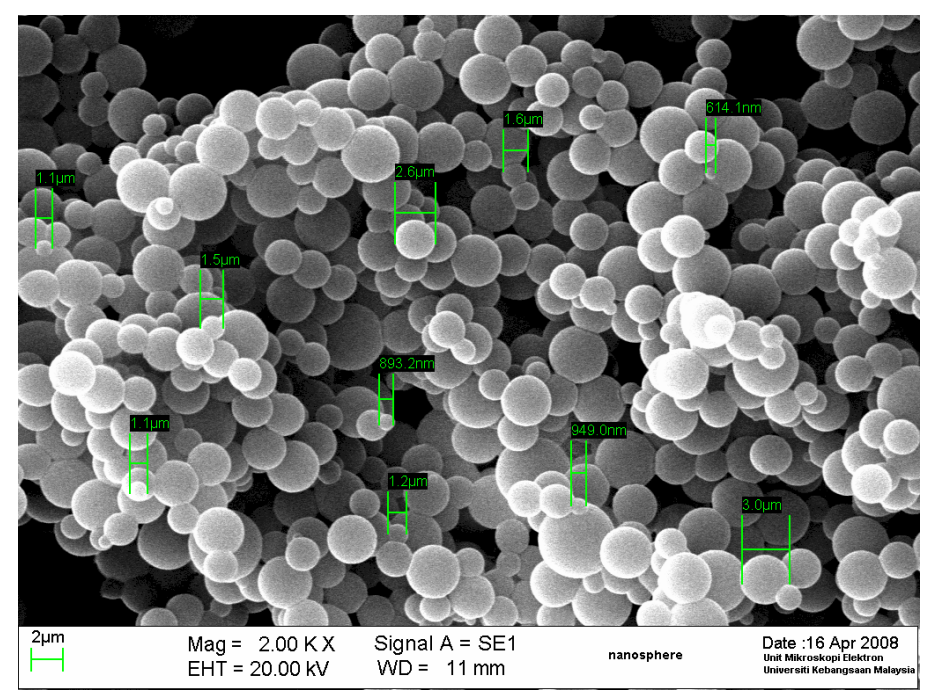

Acrylic polymers with higher amounts of n-BA tend to be more sticky and result in microsphere aggregation [26]. The effect of the amount of n-BA monomer used on the size of the microspheres was more pronounced when compared with the variation of the amount of SDS used. Based on the particle sizer determination, with a fixed amount of SDS, an increase in the n-BA from 0.5 to $7 \mathrm{~mL}$ led to an increase in the size of the microspheres from 0.32 to $271 \mu \mathrm{m}$. This may be explained by the fact that a 
higher quantity of n-BA leads to the merging of the monomer into larger droplets and hence an increase in the size of the microspheres formed after photopolymerisation. Futhermore, after formation, microspheres with higher n-BA will aggregate more, a phenomenon attributable to the increased sticky properties during particle sizer measurements, where the microspheres appeared to have increased in size. The effect of the quantity of monomer on microsphere size has been reported previously [29] and the synthesis of acrylic microsphere by photopolymerisation in a suspension performed here behaved similarly. Although the SDS used is able to stabilize the monomer droplets to prevent formation of bigger droplets during emulsion polymerisation [27,28], an increase of SDS from 0.01 to $0.05 \mathrm{~g}$ produced microspheres of similar particle sizes. The size of the microsphere used for fabricating the biosensor consists is $1-5 \mu \mathrm{m}$ based on the SEM images. The amount of $\mathrm{n}$-BA monomer used to produce this microsphere composition was able to yield spheres that possessed a good adhesion characteristics, which is essential for coating onto a substrate for optical sensor.

The response of the immobilized urease was indicated by a change of colour of the phenolphthalein indicator to red in the presence of urea. The absorption spectrum of urea solution containing urease modified microspheres is shown in Figure 3. On the other hand, a plastic support coated with acrylic microspheres without immobilized urease showed no change in color when immersed in urea solution. This confirmed that the immobilized urease was still reactive where hydrolysis of urea by the urease producing $\mathrm{NH}_{4}^{+}, \mathrm{HCO}_{3}^{-}$, and $\mathrm{OH}^{-}$, which changed the $\mathrm{pH}$ towards alkaline values. Leaching experiments have shown that no leaching of urease enzyme that was immobilized on the acrylic microspheres occurred because a buffer solution exposed to the immobilised enzyme for $90 \mathrm{~min}$ did not change color when urea and the phenolphthalein indicator were added. This suggests that a very strong binding of urease with the succinimide ester groups of NAS on the acrylic microspheres.

Figure 3. The absorbance response of the phenolphthalein indicator in the presence of acrylic microspheres and urea before immobilization with urease (a); and after immobilization (b).

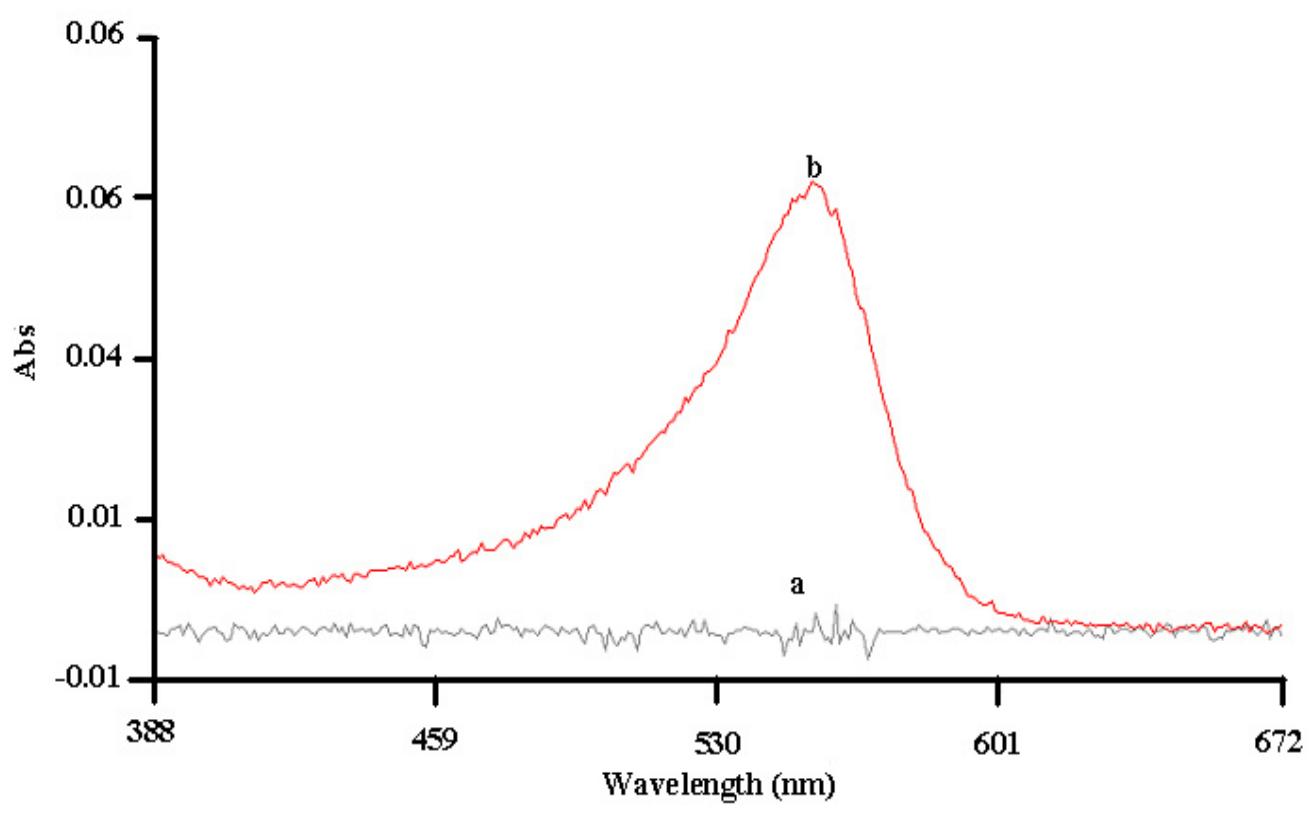




\subsection{Optimum $\mathrm{pH}$ for Enzyme Immobilization}

Optimization of $\mathrm{pH}$ conditions is essential for successful immobilization of the enzyme since a higher $\mathrm{pH}$ value will result in more amine groups being unprotonated and able to attack the succinimide ester group of the NAS moiety, but the ester is also susceptible to hydrolysis at high $\mathrm{pH}$ [22]. Figure 4 shows the effects of the use of different $\mathrm{pHs}$ for the enzyme immobilization step. The response of the biosensor increased with $\mathrm{pH}$ up to 7.0, after which it decreased with further increased in $\mathrm{pH}$, indicating that $\mathrm{pH} 7.0$ was optimum for suitable covalent binding between the amine groups of the enzyme with the succinimide ester of NAS. When the $\mathrm{pH}$ was higher than 7.0, which was outside the optimum working range of the enzyme urease, an overall decrease in the response of the measurement was thus observed. This finding is consistent with a previous report [22], which found that the amino group of urease directly reacted with the succinimide ester of NAS under the same $\mathrm{pH}$.

Figure 4. The reflectance intensity of the urease-modified microspheres prepared in the presence of different $\mathrm{pH}$ values (at $0.05 \mathrm{M}$ phosphate buffer and $10 \mathrm{mM}$ fixed urea concentration).

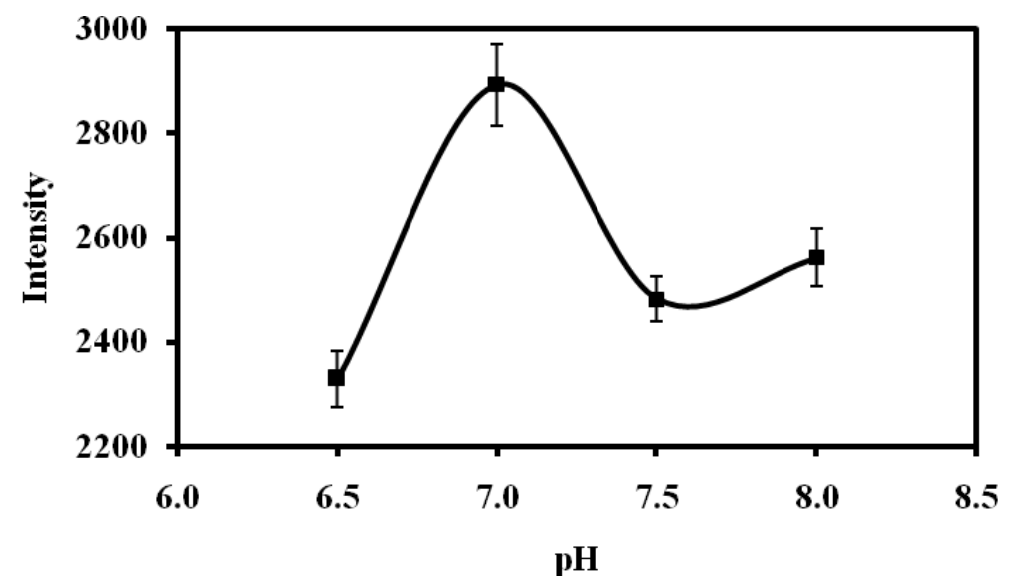

\subsection{Dependence of Biosensor Response on $\mathrm{pH}$}

Both the activity of urease and chromoionophore can be affected by $\mathrm{pH}$ of the buffer solution used, making it important to optimize the biosensor response with respect to $\mathrm{pH}$. From the Figure 5, pH 6.5 was found to give the best response in terms of sensitivity and linear range for the urea biosensor (Table 1). This $\mathrm{pH}$ yielded a maximum sensitivity from the enzymatic response. Below this $\mathrm{pH}$ the histidine group of the urease enzyme is not affected by the phosphate buffer used [30].

Table 1. The effect of $\mathrm{pH}$ on the response of the urea biosensor based on acrylic microspheres and reflectance measurements (in $0.05 \mathrm{M}$ phosphate buffer)

\begin{tabular}{cccc}
\hline $\mathbf{p H}$ & Sensitivity $(\mathbf{I} / \mathbf{m M})$ & $\mathbf{R}^{\mathbf{2}}$ & Linear range $(\mathbf{m M})$ \\
\hline 5.0 & 104.80 & 0.98 & $1.0-1,000$ \\
6.0 & 122.77 & 0.95 & $0.01-100$ \\
6.5 & 146.99 & 0.97 & $0.01-1,000$ \\
7.0 & 116.51 & 0.98 & $0.01-100$ \\
8.0 & 83.76 & 0.91 & $0.1-100$ \\
\hline
\end{tabular}


Figure 5. The effect of $\mathrm{pH}$ on the urea biosensor sensitivity.

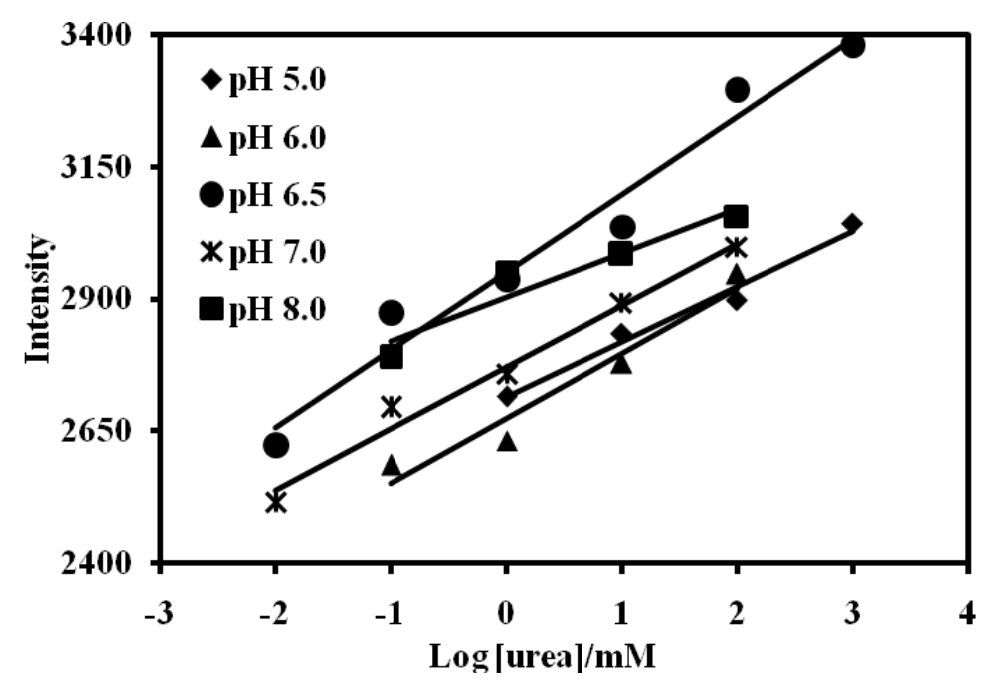

\subsection{The Effect of Loading of Acrylic Microspheres on the Response of the Urea Biosensor}

Figure 6(a) shows the urea biosensor response with different amounts of acrylic microspheres coated onto a film. The response of the biosensor towards different amounts of microspheres indicated that the use of too few or too many microspheres would lead to poor responses. When too few microspheres were used, the intensity of the colour change will be low and thus the optode is insensitive, but when too many microspheres were loaded onto the film, a tight packing of these microspheres hindered the diffusion of the urea and reaction products. These factors eventually resulted in poor biosensor response. The response of the urea biosensor is best at $6.43 \mathrm{mg}$ of acrylic microspheres for each coated film.

Figure 6. (a) The effects of the amount of acrylic microspheres coated onto a film on the urea biosensor response (measured at fixed time analysis $10 \mathrm{~min}$ ); and (b) The effects of exposure time to urea on the response of the urea biosensor (fixed amount of coated microspheres).

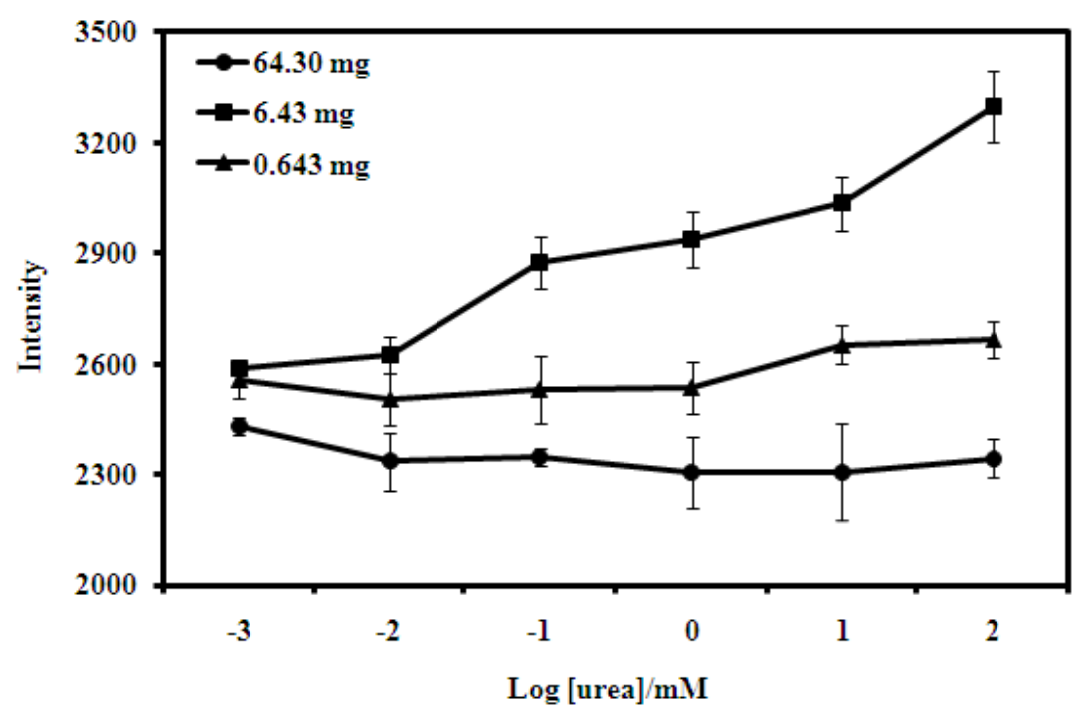

(a) 
Figure 6. Cont.

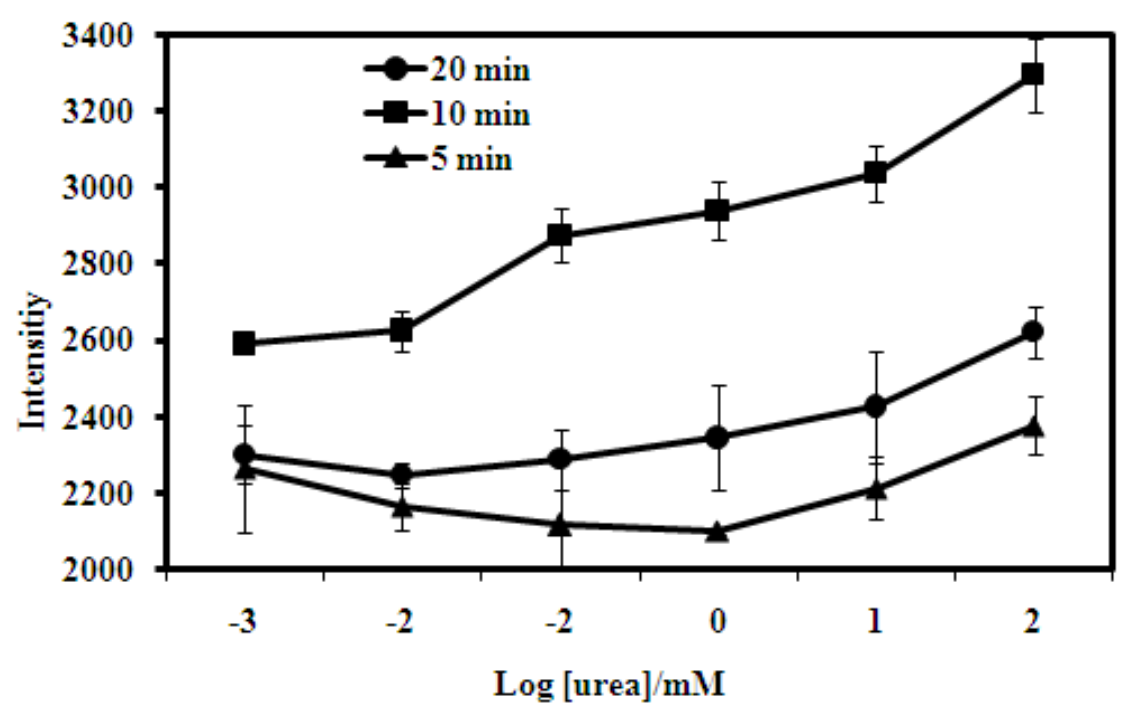

(b)

In terms of exposure time, the intensity of the colour change when the biosensor was exposed to urea was recorded after reaction times of 5, 10 and $20 \mathrm{~min}$ [Figure 6(b)]. When the intensity was taken at a short time of $5 \mathrm{~min}$, little colour change was observed, indicating that the biosensor had not undergone sufficient reaction to produce products. On the other hand, when the exposure time was too long, the colour change was too dark and this resulted in small differences in reflectance changes. Therefore, exposure time of the biosensor to urea that would yield large changes in reflectance intensity was chosen at $10 \mathrm{~min}$.

\subsection{Effects of Ionic Interference on the Optical Urea Biosensor}

Acrylic polymer itself is not responsive to ions [26] whilst the chromoionophore ETH 5294 is sensitive only to $\mathrm{pH}[6,20,31]$. Thus, above $0.01 \mathrm{mM}$ urea, there was little response of the urea biosensor to the various ions used in the interference studies when compared to the response of urea (Figure 7). It indicates that these ions do not interfere with the urea response and the biosensor was selective to urea when used in the determination of urea in the urine samples.

\subsection{Effect of Urease Immobilization Time Biosensor Response}

Figure 8 shows the amount of urease immobilized on the urea biosensor with the time employed during the process of urease immobilisation. The length of time for the immobilzation process affected the amount of enzyme immobilized onto the urea biosensor. Increasing in immobilization time obviously increased the amount of enzyme immobilized because binding of more enzyme via the succinimide ester could occur given a longer period of time. Thus, urease immobilisation on microspheres was performed over a $24 \mathrm{~h}$ period. 
Figure 7. The effect of various ions on the response of the optical urea biosensor based on acrylic microspheres and reflectance transduction.

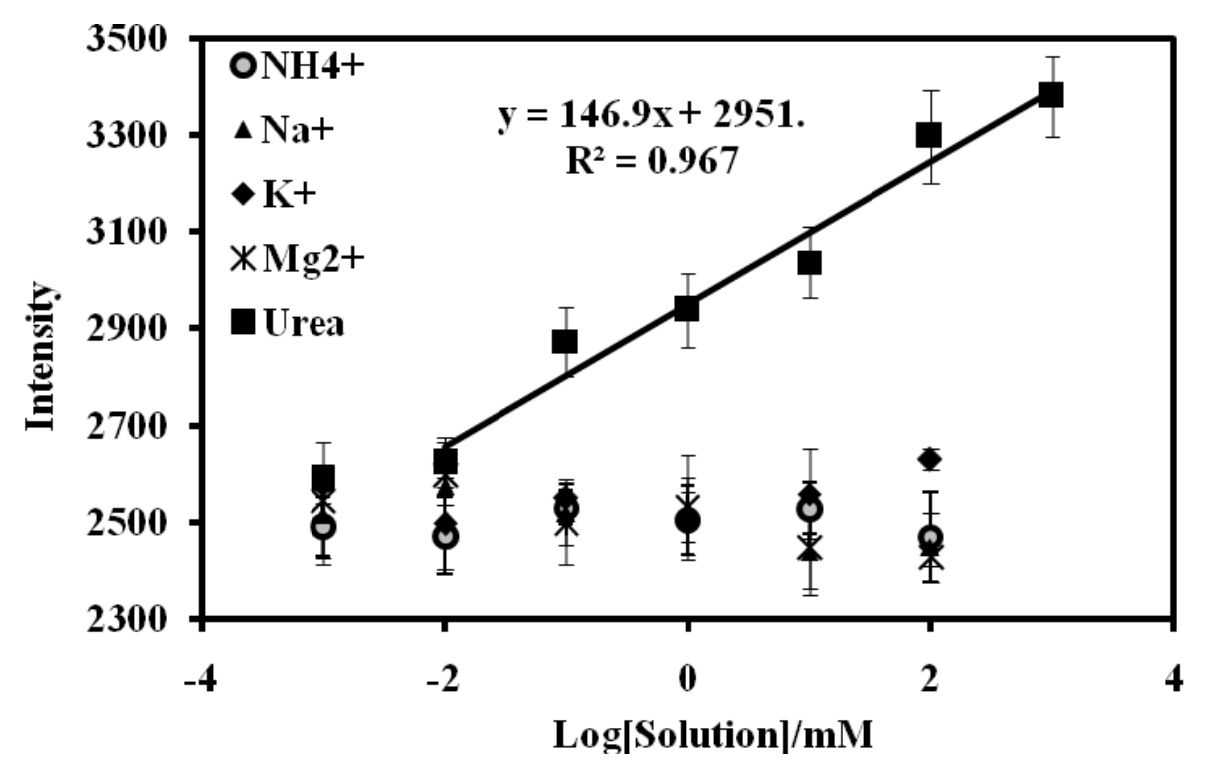

Figure 8. The amount of urease immobilized onto the urea biosensor at various immobilization times.

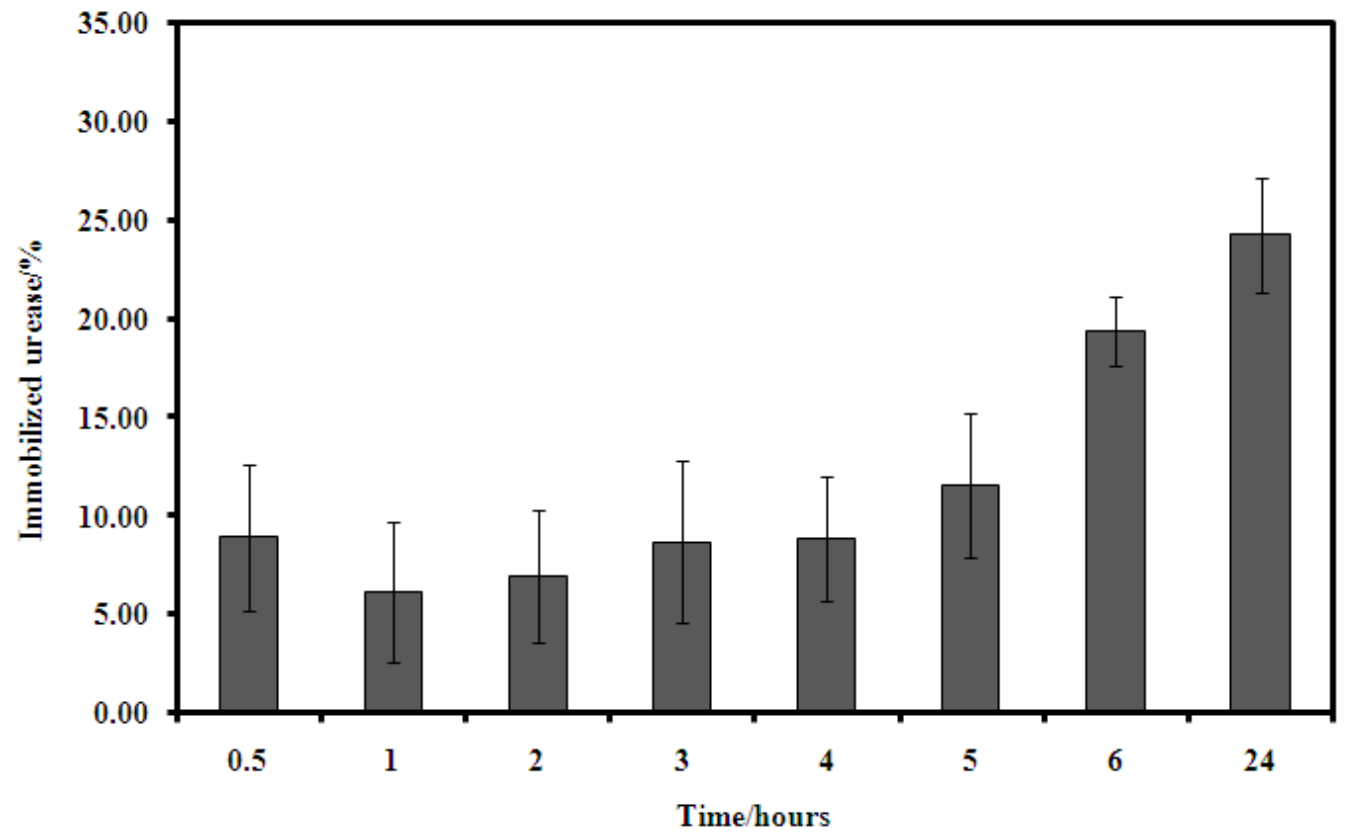

\subsection{Validation and Recovery of Optical Urea Biosensor}

Figure 9 correlates the results using the urea biosensor and the DMAB methods for urea determined in the urine sample. A good correlation coefficient $\left(\mathrm{R}^{2}=0.997\right)$ and slope $(1.18)$ for responses of the urea biosensor and DMAB methods to urea concentration was observed, indicating that the urea biosensor developed in this work can be used for the measurement of urea concentrations in urine samples. 
Figure 9. Urea concentrations in urine samples as determined by biosensor and DMAB.

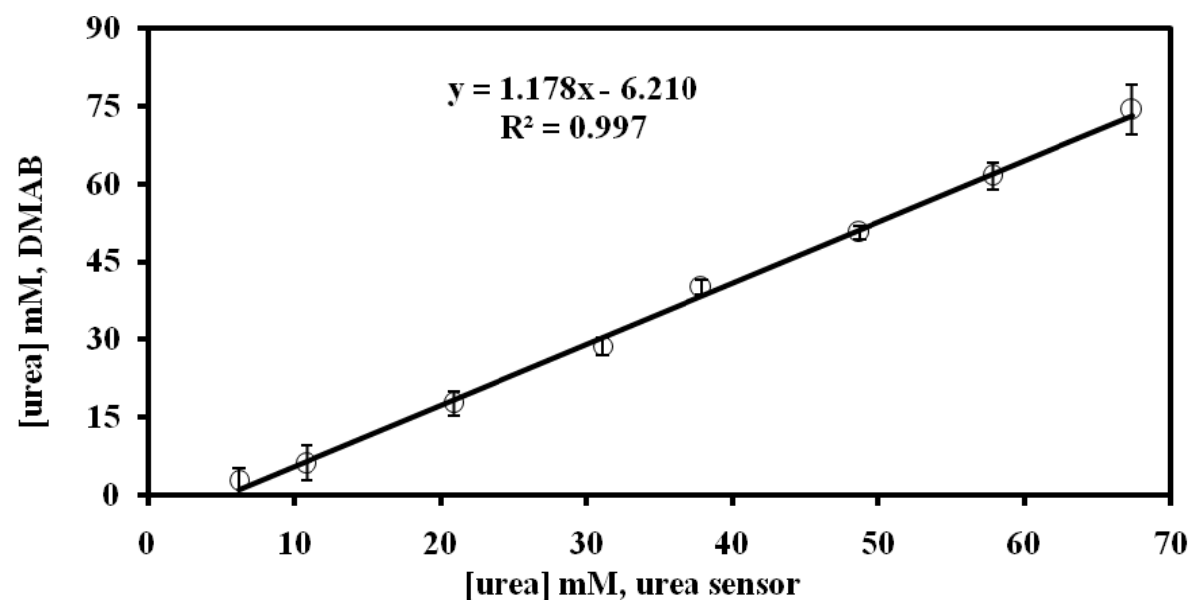

Recovery by the urea biosensor is a very important indication of the accuracy of its detection of urea concentration in real samples of urine. Normally, the kidney excretes urea into the urine at 6 to $90 \mathrm{mg} / \mathrm{dL}$ (10.0 to $15.0 \mathrm{mM}$ ) [6]. Since the variation in level of urea in urine reflects the health of the kidney, therefore it is very important that the biosensor be able to determine the urea in urine very accurately. Table 2 shows the recovery of the optical urea biosensor containing different spiked urea concentrations in urine. The average recovery percentage of the urea biosensor across the concentrations of urea was $94.91 \%$ to $118.73 \%$ indicating no clear interference during determination of urea in urine samples by the optical biosensor.

Table 2. Recovery performance of urea biosensor for urine samples spiked with urea at different concentrations $(n=3)$.

\begin{tabular}{ccc}
\hline $\begin{array}{c}\text { Concentration of } \\
\text { spiked urea }(\mathbf{m M})\end{array}$ & $\begin{array}{c}\text { Concentration of urea as } \\
\text { determined by urea biosensor } \mathbf{( m M )}\end{array}$ & $\begin{array}{c}\text { \% of recovery } \\
\text { by urea biosensor }\end{array}$ \\
\hline 0 & 14.87 & - \\
1.01 & 1.20 & 118.73 \\
19.99 & 20.90 & 104.58 \\
39.97 & 37.94 & 94.91 \\
49.96 & 48.72 & 97.51 \\
69.94 & 67.42 & 96.40 \\
\hline
\end{tabular}

\subsection{Reproducibility and Stability of Urea Biosensor}

The reproducibility of the urea biosensor was satisfactory, with a small RSD of $1.43 \%$. In terms of stability, the reflectance intensity of the biosensor was stable and remained at about $100 \%$ for the first 15 days and thereafter it was still remained at $87.01 \%$ and $82.37 \%$ of the initial intensity on day- 1 for $1.0 \mathrm{mM}$ and $10.0 \mathrm{mM}$ urea, respectively, until the 45th day (Figure 10). The sensitivity of an optical urea biosensor based on sol-gel entrapment of urease enzyme was observed to decrease to $45 \%$ after 28 days storage [20]. The improvement in the long term stability of the optical urea biosensor based on acrylic microspheres was attributed to the covalent immobilization of the enzyme on the microsphere surface. 
Figure 10. The stability of the urea biosensor response over a period of 45 days (in $0.05 \mathrm{M}$ phosphate buffer solution at $\mathrm{pH} 7.0$ containing 1.0 and $10.0 \mathrm{mM}$ urea).

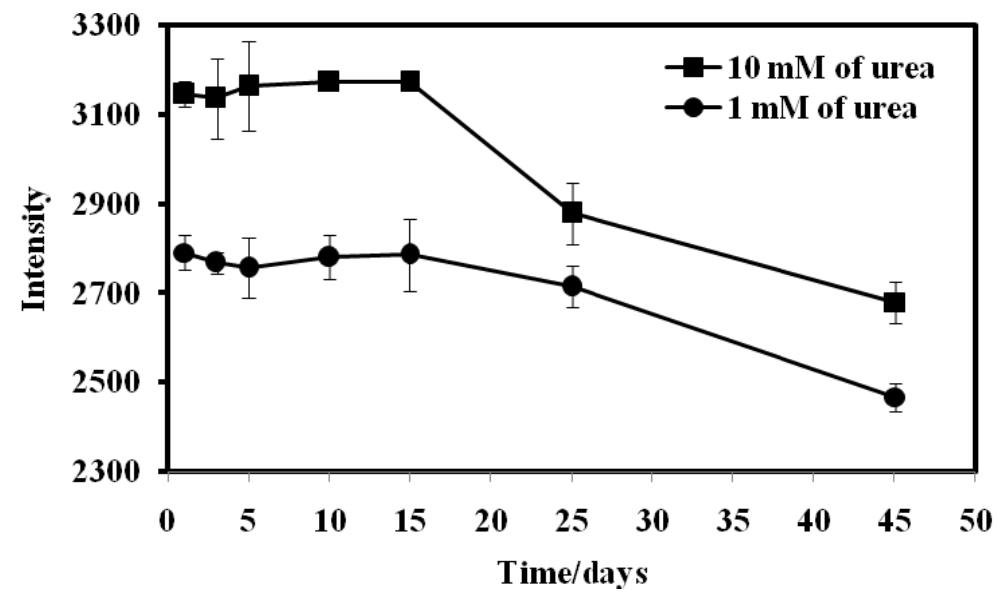

\subsection{Comparison with Other Urea Biosensors}

Table 3 presents a detailed comparison of optical urea biosensors reported in the literature with the biosensor reported in this work. By comparison, the urea biosensor presented in this work using acrylic microspheres as the immobilization matrix demonstrated a larger linear response range when compared to other types of optical based urea biosensors using various enzyme immobilization matrices. The acrylic microspheres based urea biosensor using reflectance transduction also compared favorably with other reported optical urea biosensors in terms of detection limit and response time.

Table 3. A comparison of optical urea biosensor with previously reported urea biosensors.

\begin{tabular}{lcccc}
\hline Urease immobilisation & $\begin{array}{c}\text { Linear range } \\
(\mathbf{m M} \mathbf{)}\end{array}$ & $\begin{array}{c}\text { Limit of } \\
\text { detection } \mathbf{( m M )}\end{array}$ & $\begin{array}{c}\text { Response } \\
\text { time(min) }\end{array}$ & Reference \\
\hline Acrylic microspheres & $0.01-1,000$ & 0.01 & 10 & This work \\
Sol-gel films & $5-100$ & 0.01 & 10 & {$[6]$} \\
Poly(vinyl chloride) film & $0.1-1$ & - & 0.33 & {$[20]$} \\
Sol-gel encapsulation & $0.0025-0.05$ & 0.0025 & 10 & {$[32]$} \\
Alginate microspheres & $0.1-60$ & 0.1 & 8 & {$[33]$} \\
Poly(vinyl chloride) membrane & $0.3-100$ & 0.3 & 3 & {$[34]$} \\
Polypyrrole-polyvinyl sulphonate film & $1-100$ & - & - & {$[35]$} \\
\hline
\end{tabular}

\section{Conclusions}

An optical urea biosensor was successfully developed using acrylic microspheres as a matrix for urease immobilization. Urease enzyme can be immobilized onto the acrylic microspheres because of the introduction of NAS for enzyme binding onto the microsphere surface. In general the use of these microspheres coupled with reflectance transduction yielded a urea biosensor with an extended linear response range when compared with other reported optical urea biosensors, whilst maintaining similar detection limit, response time, selectivity and reproducibility. Besides that the optical urea biosensor is demonstrated to be suitable for measuring the concentration of urea in urine with good recovery when compared to the standard spectrophotometric method DMAB for the analysis of urine. 


\section{Acknowledgements}

We would like to thank Universiti Kebangsaan Malaysia for its support of this research through funding under the University Operational Research Grant UKM-OUP-NBT-29-151/2011.

\section{References}

1. Liu, B.; Hu, R.; Deng, J. Studies on a potentiometric urea biosensor based on an ammonia electrode and urease, immobilized on a $\gamma$-aluminium oxide matrix. Anal. Chim. Acta 1997, 341, 161-169.

2. Trivedi, U.B.; Lakshminarayana, D.; Kothari, I.L.; Patel, N.G.; Kapsed, H.N.; Makhija, K.K.; Patel, P.B.; Panchale, C.J. Potentiometric biosensor for urea determination in milk. Sens. Actuat. B 2009, 140, 260-266.

3. Lee, W.Y.; Kim, S.R.; Kim, T.H.; Lee, K.S.; Shin, M.C.; Park, J.K. Sol-gel-derived thick-film conductometric biosensor for urea determination in serum. Anal. Chim. Acta 2000, 404, 195-203.

4. Luo, Y.C.; Do, J.S. Urea biosensor based on PANi (urease) ${ }^{\mathbb{R}} / \mathrm{Au}$ composite electrode. Biosens. Bioelectron. 2004, 20, 15-23.

5. Singhal, R.; Gambhir, A.; Pandey, M.K.; Annapoorni, S.; Malhotra, B.D. Immobilization of urease on poly(N-vinyl carbazole)/stearic acid Langmuir-Blodgett films for application to urea biosensor. Biosens. Bioelectron. 2002, 17, 697-703.

6. Muawia, S.A.; Lee, Y.H.; Musa, A. A urea biosensor from stacked sol-gel films with immobilized Nile blue chromoionophore and urease enzyme. Sensor 2007, 7, 2251-2262.

7. Senillou, A.; Renault, N.J.; Martelet, C.; Consnier, S. A miniaturized urea sensor based on the integration of both ammonium based urease enzyme field effect transistor and a reference field effect transistor for in a single chip. Talanta 1999, 50, 219-226.

8. Yashuda, K.; Miyagi, H.; Hamada, Y.; Takata, Y. Determination of urea in whole blood using a urea electrode with immobilized urease membrane. Analyst 1984, 109, 61-64.

9. Guilbault, G.G.; Shu, F.R. Enzyme electrode based on the use of carbon dioxide sensor. Anal. Chem. 1972, 44, 2161-2165.

10. Ruzicka, J.; Hansen, E.H.; Ghose, K. Enzymatic determination of urea in serum based on $\mathrm{pH}$ measurement with flow injection method. Anal. Chem. 1979, 51, 199-206.

11. Guilbault, G.G.; Trap, M.A. Specific enzyme electrode for urea. Anal. Chim. Acta 1974, 73, 355-365.

12. Magalhães, J.M.; Machado, A.A. Urea potentiometric biosensor based on urease immobilized on chitosan membranes. Talanta 1998, 47, 183-191.

13. Gouda, M.D.; Kumar, M.A.; Thakur, M.S.; Karanth, N.G. Enhancement of operational stability of an enzyme biosensor for glucose and sucrose using protein based stabilizing agents. Biosens. Bioelectron. 2002, 17, 503-507.

14. Lakard, B.; Herlem, G.; Lakard, S.; Antoniou, A.; Fahys, B. Urea potentiometric biosensor based on modified electrodes with urease immobilized on polyethylenimine films. Biosens. Bioelectron. 2004, 19, 1641-1647. 
15. Singh, M.; Verma, N.; Kumar Garg, A.; Redhu, N. Urea biosensors. Sens. Actuat. B 2008, 134, 345-351.

16. Xu, S.; Han, X. A novel method to construct a third-generation biosensor: Self-assembling gold nanoparticles on thiol-functionlized poly(styrene-co-acrylic acid) nanospheres. Biosens. Bioelectron. 2004, 19, 1117-1120.

17. Xu, S.; Tu, G.; Peng, B.; Han, X. Self-assembling gold nanoparticles on thiol-functionalized poly(styrene-co-acrylic acid) nanospheres for fabrication of a mediatorless biosensor. Anal. Chim. Acta 2006, 570, 151-157.

18. Xu, S.; Peng, B.; Han, X. A third-generation $\mathrm{H}_{2} \mathrm{O}_{2}$ biosensor based on horseradish peroxidase-labeled $\mathrm{Au}$ nanoparticles self-assembled to hollow porous polymeric nanopheres. Biosens. Bioelectron. 2007, 22, 1807-1810.

19. Wong, F.C.M.; Ahmad, M.; Heng, L.Y.; Peng, L.B. An optical biosensor for dichlovos using stacked sol-gel containing acetylcholinesterase and a lipophilic chromoionophore. Talanta 2006, 69, 888-893.

20. Kovács, B.; Nagy, G.R.; Dombi, R.; Tóth, K. Optical biosensor for urea with improve response time. Biosens. Bioelectron. 2003, 18, 111-118.

21. Wofbies, O.S.; Li, H. Fluorescence optical urea biosensor with an ammonium optrode as transducer. Biosens. Bioelectron. 1993, 8, 161-166.

22. Chen, J.P.; Chiu, S.H. A poly(N-isopropylacrylamide-co-N-acryloxysuccinimede-co-2-hydroxyethyl methacrylate) composite hydrogel membrane for urease immobilization to enhance urea hydrolysis rate by temperature swing. Enzym. Micro. Technol. 2000, 26, 359-367.

23. Chaix, C.; Pacard, E.; Elaissari, A.; Hilaire, J.F.; Picot, C. Surface functionalization of oil-in-water nanoemulsion with a reactive copolymer: Colloidal characterization and peptide immobilization. Colloids Surf. B 2002, 29, 39-52.

24. Zor, T.; Selinger, Z. Linearization of the bradford protein assay increases its sensitivity: Theoretical and experimental studies. Anal. Biochem. 1996, 36, 302-308.

25. Williams, S. Official Methods of Analysis of the Association of Official Analytical Chemists; Association of Official Analytical Chemists: Colombia, MD, USA, 1984.

26. Lee, Y.H.; Hall, E.A.H. Methacrylic-acrylic polymers in ion-selective membranes: Achieving theright polymer recipe. Anal. Chim. Acta 2000, 403, 77-89.

27. Landfester, K.; Schork, F.J.; Kusuma, V.A. Particle size distribution in mini-emulsion polymerization. Compt. Rendus Chim. 2003, 6, 1337-1342.

28. Liu, X.Q.; Guan, Y.P.; Liu, H.Z.; Ma, Z.Y.; Yang, Y.; Wu, X.B. Preparation and characterization of magnetic polymer nanospheres with high protein binding capacity. J. Magn. Magn. Mater. 2005, 293, 111-118.

29. Usmani, A.; Akmal, N. Diagnostic Biosensor Polymer; ACS Symposium Series 556; American Chemical Society: Washington, DC, USA, 1994.

30. Krajewska, B.; Zaborska, W. The effect of phosphate buffer in the range of pH 5.80-8.07 on jack bean urease activity. J. Mol. Catal. B: Enzym. 1999, 6, 75-81.

31. Francis, C.M.W.; Musa, A.; Lee, Y.H.; Lim, B.P. An optical biosensor for dichlovos using stacked sol-gel films containing acetylcholinesterase and a lipophilic chromoionophore. Talanta 2006, 69, 888-893. 
32. Tsai, H.C.; Dong, R. Simultaneous determination of $\mathrm{pH}$, urea, acethylcholine and heavy metals using array-based enzymatic optical biosensor. Biosens. Bioelectron. 2005, 20, 1796-1804.

33. Swati, M.; Hase, N.K.; Srivastava, R. Nanoengineered optical urea biosensor for estimating hemodialysis parameters in spent dialysate. Anal. Chim. Acta 2010, 676, 68-74.

34. Koncki, R.; Mohr, G.J.; Wolfe's, O.S. Enzyme biosensor for urea based on a novel pH bulk optode membrane. Biosens. Bioelectron. 1995, 10, 653-659.

35. Kharat, H.J.; Datta, K.; Ghosh, P.; Shirsat, M.S. Development of an optical urea biosensor using polypyrrole-polyvinyl sulphonate film. Sens. Trans. J. 2009, 101, 112-122.

(C) 2011 by the authors; licensee MDPI, Basel, Switzerland. This article is an open access article distributed under the terms and conditions of the Creative Commons Attribution license (http://creativecommons.org/licenses/by/3.0/). 